\title{
Antigen-Presenting Cells and Antigen Presentation in Tertiary Lymphoid Organs
}

\author{
Catherine E. Hughes ${ }^{1}$, Robert A. Benson ${ }^{1}$, Marija Bedaj ${ }^{1,2}$ and Pasquale Maffia ${ }^{1,3,4 *}$ \\ ${ }^{1}$ Centre for Immunobiology, Institute of Infection, Immunity and Inflammation, College of Medical, Veterinary and Life \\ Sciences, University of Glasgow, Glasgow, UK, ${ }^{2}$ Rheumatology Research Group, Centre for Translational Inflammation \\ Research, School of Immunity and Infection, College of Medical and Dental Sciences, University of Birmingham, \\ Birmingham, UK, ${ }^{3}$ BHF Centre of Excellence in Vascular Science and Medicine, College of Medical, Veterinary and Life \\ Sciences, University of Glasgow, Glasgow, UK, ${ }^{4}$ Department of Pharmacy, University of Naples Federico II, Naples, Italy
}

OPEN ACCESS

Edited by:

Fulvio D'Acquisto,

Queen Mary University

of London, UK

Reviewed by:

Yolande Richard,

French Institute of Health and Medical Research, France Maria Laura Belladonna,

University of Perugia, Italy

*Correspondence: Pasquale Maffia pasquale.maffia@glasgow.ac.uk

Specialty section: This article was submitted to Inflammation,

a section of the journal

Frontiers in Immunology

Received: 28 August 2016 Accepted: 20 October 2016 Published: 07 November 2016

Citation:

Hughes CE, Benson RA, Bedaj M and Maffia P (2016) Antigen-Presenting Cells and

Antigen Presentation in

Tertiary Lymphoid Organs.

Front. Immunol. 7:481. doi: 10.3389/fimmu.2016.00481
Tertiary lymphoid organs (TLOs) form in territorialized niches of peripheral tissues characterized by the presence of antigens; however, little is known about mechanism(s) of antigen handling by ectopic lymphoid structures. In this mini review, we will discuss the role of antigen-presenting cells and mechanisms of antigen presentation in TLOs, summarizing what is currently known about this facet of the formation and function of these tissues as well as identifying questions yet to be addressed.

Keywords: antigen presentation, antigen-presenting cells, B cells, dendritic cells, follicular dendritic cells, macrophages, tertiary lymphoid organs

\section{INTRODUCTION}

The ability to respond rapidly and effectively to damage or infection is mediated by the immune system. Secondary lymphoid organs (SLOs) such as lymph nodes (LNs) and spleen provide critical meeting points for immune cells and antigens, promoting interactions that result in a prompt, targeted immune response. A key process in initiating and sustaining such an adaptive response is in the delivery of antigen for interrogation by lymphocyte populations. Networks of lymphatic vessels channel free and cell-borne antigen to the lymph node where it is then further directed to appropriate lymphocyte compartments through additional structural and cellular filters. However, during chronic inflammation, ectopic lymphoid tissue can form in the periphery, outside the normal sites of secondary lymphoid organogenesis. This tissue shares common features with SLOs, including segregated $\mathrm{T}$ and $\mathrm{B}$ cell areas, germinal centers (GCs), development of structural stromal components, and vascularization, with high endothelial venules (HEVs) often observed (1). These so-called tertiary lymphoid organs (TLOs) are thought to function as a local site for perpetuation of adaptive immune responses providing a local source of antibody, generated as the result of local antigen presentation, and lymphocyte activation and maturation in the newly formed structure. In some settings, development of these lymphoid structures may be advantageous, as in bacterial and viral infections $(2-4)$, atherosclerosis $(5,6)$, and cancer $(7,8)$, while in a number of diseases, particularly autoimmune disorders, the development of TLOs may be associated with non-resolving inflammation, with a vigorous and sustained response to self-antigen amplifying severe and chronic pathology [reviewed in Ref. (9); see also Ref. (10-12)]. In this review, we will outline the role of antigen-presenting cells (APCs) and mechanisms of antigen presentation in the TLO, summarizing what is currently known about this facet of the formation and function of these tissues as well as identifying questions yet to be addressed. 
A spectrum of TLO development has been documented in the literature, with ectopic lymphoid tissue ranging from relatively loose aggregates of B and T cells to highly compartmentalized, complex structures that include stromal scaffolding supporting distinct $\mathrm{T}$ cell zones and secondary $\mathrm{B}$ cell follicles containing GCs, i.e., bona fide lymphoid organs with clear parallels to secondary lymphoid tissue $(9,13)$. The initial steps leading to development of TLOs are unclear, as a number of distinct but inter-related signals can prompt development of organized lymphoid structures in non-lymphoid tissue. Determining the "tipping point" beyond which development of functional, relatively stable ectopic lymphoid tissue is inevitable is inherently difficult. However, a number of features are known to affect formation and stability of the structure. Several studies, described in more detail elsewhere in this research topic issue, variously indicate increased expression of cytokines such as lymphotoxin (LT) and other TNF family members (14), IL-22 (15), and chemokines such as CXCL13 and CCL21 (16-18) as being capable of inducing TLO formation. In a patho-physiological setting, specific cell types (19), including T cells (16), and APCs, such as macrophages (20), dendritic cells (DCs) $(2,3)$, and activated B cells (21), are all described as possible key players in early expression of cytokines and chemokines that promote increased tissue infiltration by leukocytes, development of lymphoid stromal cells such as follicular dendritic cells (FDCs), and construction and maintenance of the functional TLO. Fluid accumulation at the site of infection has also been suggested to influence TLO development (22).

\section{ANTIGEN-PRESENTING CELL POPULATIONS WITHIN TLOS}

\section{Dendritic Cells}

Although an ever-increasing number of cell types have been shown to be capable of presenting antigen to immune cells, the classical professional antigen-presenting cell is the conventional dendritic cell (23).

Their involvement in various types of TLO has been demonstrated by a number of studies. In a model of viral lung infection, Halle et al. (2) showed that early infiltration of $\mathrm{CD}_{11 \mathrm{c}^{+}}$cells into the perivascular and peribronchiolar space (4 days post infection) precipitated recruitment of lymphocytes to the infected tissue, with subsequent development of organized inducible bronchus-associated lymphoid tissue (iBALT) structures. Within these highly developed structures, DCs resided primarily within the $\mathrm{T}$ cell area, as in SLOs. When CD $11 c^{+}$cells were selectively depleted at various time points using a diphtheria toxin receptor (DTR) transgenic model, the size, but not frequency, of iBALT was reduced, suggesting an important role for DCs, and possibly alveolar macrophages, in maintaining TLO integrity (2). A concurrent study, investigating induction of iBALT in a model of influenza infection, also

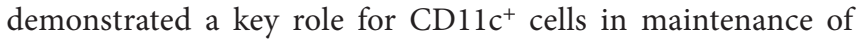
these lymphoid structures. Again, using a DTR-transgenic model, this study showed that selective depletion of $\mathrm{CD} 11 \mathrm{c}^{+}$ cells from lungs with mature iBALT led to disintegration of the TLO and gradual dispersal of lymphocytes from the lung (3). Notably, influenza-specific plasma cells were found to be undetectable soon after DT-induced depletion of CD11 $\mathrm{c}^{+}$cells, while total B cells and peanut agglutinin $(\mathrm{PNA})^{+} \mathrm{GC} B$ cells were also substantially reduced. The level of class-switched immunoglobulin, specifically $\operatorname{IgA}$, was also significantly reduced in bronchoalveolar lavage fluid. These results indicate a prominent role for DCs in the function and maintenance of iBALT following influenza infection, as well as suggesting an important role for the TLO in local production of class-switched antibodies. Somewhat surprisingly, depletion of $\mathrm{CD}_{11 \mathrm{c}^{+}}$cells also led to a significant reduction in the level of systemic hemagglutininspecific antibody present, indicating a potential role for TLO GCs in generation of long-lived plasma cells that home to the bone marrow (BM). To investigate the role of antigen presentation by DCs in this tissue, lung DCs were isolated from animals challenged with influenza virus expressing the MHC-II OVA $_{323-339}$ epitope, at days 4 and 17 post infection. While these DCs were able to activate OVA-specific $\mathrm{CD}^{+}$ T cells (OT-II) at day 4, this was no longer the case at the later time point. However, they retained antigen-presenting ability, as demonstrated by DC-mediated activation of OT-II cells after addition of pre-processed OVA peptide. The authors suggest that the primary role of the DC population in maintenance of the iBALT is production of LT $\beta$, which in turn induces high levels of CXCL13, an important chemokine in B cell migration and retention. Finally, the study also demonstrated that adoptive transfer of granulocyte-macrophage colony-stimulating factor (GM-CSF)-cultured BM-derived cells (a mix of conventional DCs and monocyte-derived macrophages) intratracheally into the lungs of naïve mice leads to iBALT development (3).

In a model of thyroid TLO development, where high levels of CCL21 were artificially induced in the thyroid, $\mathrm{CD}^{+} \mathrm{CD} 4^{+}$ $\mathrm{T}$ cells from an adoptively transferred mixed splenocyte population were found to be the initiating cell type in development of ectopic lymphoid tissue. Subsequent recruitment of host DCs and $\mathrm{DC} / \mathrm{T}$ cell interactions were found to be important for the formation of peripheral-node addressin-positive $\left(\mathrm{PNAd}^{+}\right)$ HEVs in the developing TLO, in a LT $\alpha$-/LT $\beta$ R-dependent manner (16). A subsequent paper by the same group confirmed that depletion of CD11 $\mathrm{c}^{+}$DCs led to reduced lymphangiogenesis in the thyroid (24).

LT $\beta R$ is known to have an important role in the maintenance of HEVs within LNs (25), again indicating that these structures are bona fide lymphoid organs. Interestingly, in a model of insulin-dependent diabetes mellitus induced by adoptive transfer of specific antigen-expressing DCs, only mice that showed early infiltration of leukocytes and formation of islet-associated organized lymphoid structures in the pancreatic parenchyma went on to develop diabetes, suggesting a link between antigen presentation by DCs to T cells, TLO formation, and development of autoimmunity (26). More recently, the presence of mature DCs in tumor TLOs was highly associated with a favorable clinical outcome in patients with lung cancers $(27,28)$; however, to date, there is no direct demonstration that APCs in TLOs permit efficient local T-cell priming against tumor-associated antigens. 


\section{Macrophages}

Macrophages are some of the earliest immune cells to encounter antigen at sites of infection or injury. The response to antigenic stimulus is context-dependent but production of inflammatory cytokines is a key function of these cells in the early stages of inflammation. In the case of atherosclerosis, macrophages that infiltrate the early plaque take up oxidized low-density lipoprotein (ox-LDL) particles and are activated, including upregulation of antigen-presentation genes and increased production of inflammatory cytokines (29). Recently, work from Guedj et al. has proposed a role for pro-inflammatory macrophages as a kind of lymphoid tissue inducer (LTi) cell in the development of artery tertiary lymphoid organs (ATLOs) during atherosclerosis. In this study, BM-derived macrophages were incubated with both LPS and IFN $\gamma$ to yield a "pro-inflammatory" phenotype or with IL-4 to generate "alternatively activated" macrophages. Vascular smooth muscle cells (VSMCs) incubated with LPS/IFN $\gamma$-stimulated macrophages, which produced TNF $\alpha$ and LT $\alpha$, developed a lymphoid tissue organizer (LTo) phenotype, while those incubated with IL-4stimulated macrophages did not (20). This activity did not require LT $\beta R$ signaling but was dependent on TNF receptor involvement. In addition, Jupelli et al. (4) have reported that iNOS-expressing macrophage involvement in early stages of bacterial lung infection precedes development of iBALT in the lungs of infected mice in their model. Intratracheal transfer of "pro-inflammatory" macrophages (generated from BM-derived macrophages cultured with IFN $\gamma$ ) into infected lungs leads to increased lung inflammation and iBALT formation. It should be also noted that, although the recruitment of CD11 $\mathrm{c}^{+} \mathrm{DCs}$ is clearly a crucial step in the development of iBALT in the viral infection model from Halle et al. (2), the earliest infiltrate recorded was that of alveolar macrophages, within 5-7 h of infection, with DC accumulation described from 4 days post infection. As TLOs, by their nature, form during inflammatory events, and particularly during sustained inflammation, it is logical to assume that macrophage production of inflammatory cytokines following antigen encounter is a necessary, but probably not sufficient, primary event in TLO formation. As described for ATLO formation, a possible role for macrophages as a type of inducible LTi remains to be demonstrated for other types of ectopic lymphoid tissues.

\section{B Cells}

The main role of $\mathrm{B}$ cells in an immune response is production of antibodies. B cell presentation of antigen to T cells is an integral aspect of this function. These interactions allow $\mathrm{B}$ cells to receive survival signals and direct them appropriately to generate high affinity antibody specific to the antigen encountered (30). Wellestablished, highly organized TLOs contain secondary B cell follicles, which form following antigen encounter and activation of B cells (31-33). The GCs of these follicles are structurally and functionally similar to those within SLOs, with FDC development described within a number of ectopic lymphoid tissues. This lends credence to the hypothesis that TLOs provide a venue for local production of antibody proximal to the site of inflammation, with either beneficial (e.g., during infection, cancer, or atherosclerosis) or deleterious (e.g., autoimmunity) effects depending on the context in which the TLO forms.

B cells are involved in FDC development (34) in a LT- and TNF-dependent manner, with B cell aggregates shown to induce FDC through LT $\alpha 1 \beta 2$ production in SLOs $(35,36)$. LT $\alpha 1 \beta 2$ expression by naïve B cells is induced by CXCL13 (also known as B-lymphocyte chemoattractant), which is itself induced by LT $\alpha 1 \beta 2$ in a positive feedback loop (37), with FDCs likely the major source of CXCL13 in the follicle (36). In mice with B cells lacking LT $\beta$, FDC structures in the spleen were disrupted, though not wholly absent (13). Similarly, LT $\alpha$ is not fully required for formation of iBALT, as lymphocytic aggregates form in influenzainfected $\mathrm{Lta}^{-/-}$mice and lymphoid chemokines CXCL13 and CCL21 are detectable. However, these structures lack the level of development and organization of the TLO observed in mice expressing LT $\alpha$ (17). A similar role in promoting FDC formation has been suggested for B cells in TLOs that arise in the salivary glands of Sjögrens syndrome patients (38).

\section{Follicular Dendritic Cells}

Follicular dendritic cells are cells of the immune system found in $\mathrm{B}$ cell follicles. FDCs are integral to the function of the follicle, presenting antigen in the form of immune complexes bound to their surface $(39,40)$. FDCs are believed to provide a uniquely long-lasting "depot" of antigen that can be accessed by B cells well beyond clearance of the initial infection or injury from which the antigen was acquired. They are thought to be important in the affinity maturation of the B-cell receptor (BCR). Only B cells expressing a receptor of high enough affinity will be successful in acquiring sufficient antigen from the FDC to in turn present the antigen to their cognate $T$ cell and receive survival signals (36). A recent study has shown that disruption of the FDC network in a model of arthritis led to reduced GC formation in lymphoid follicles, impaired recruitment of follicular helper T (Tfh) cells into B cell areas, diminished autoantibody production, and attenuation of disease (41).

Although there is some debate over how B cells within a TLO might perceive antigen due to the likelihood of increased availability of local antigen compared to SLOs, a number of studies have identified FDCs within ectopic lymphoid structures (5, 42-45). The source of these cells within TLOs is unclear, but, as discussed above, various studies indicate that B cell production of LT $\alpha 1 \beta 2$ is important for differentiation of FDCs within ectopic lymphoid organs $(1,35,38)$, even though follicle formation in BALT has been reported also in the absence of differentiated FDCs (46). In addition to providing a platform for antigen presentation, FDCs are also known to produce a variety of cytokines and chemokines involved in B cell migration survival and proliferation, as well as recruitment of Tfh cells into B cell areas, such as CXCL13, BAFF, IL-15, and IL-6 $(45,47)$. Therefore, a similarly multi-faceted role for these cells in mature TLOs is anticipated.

\section{Other Antigen-Presenting Cells}

As reviewed by Kambayashi and Laufer recently, a number of cells not traditionally considered "professional" APC may nonetheless under specific circumstances be induced to express MHC-II on their surface and have been shown to 
interact with $\mathrm{T}$ cells in an antigen-specific manner $(23,48)$. In Sjögrens syndrome, salivary gland epithelial cells (SGECs) may play an important role in the presentation of self-antigen. Numerous lines of evidence point to this ability, including expression of co-stimulatory molecules, such as CD80, CD86, and CD40 $(49,50)$, the ability to express adhesion molecules and human leukocyte antigen (HLA)-DR (51), and the ability to activate antigen-specific $\mathrm{T}$ cells (48). Ishimaru et al. also suggest expression of IFN $\gamma$ by SGECs may be involved in increased expression of MHC-II by these cells (48). Self-antigen presentation by thyroid epithelial cells - indicated by MHC-II expression and an ability to induce $\mathrm{T}$ cell activation - was described more than 30 years ago, with the authors suggesting that the cells might preferentially present self-antigen (52). Other non-hematopoietic cells have also been implicated in presentation of self-antigen. In 2010, Cohen and colleagues described a role for lymphatic endothelial cells (LECs) in the induction of peripheral tolerance through autoimmune regulator (AIRE)-independent presentation of self-antigen (53). Additionally, extrathymic AIRE-expressing cells (eTACs) have been identified in pancreatic TLO of non-obese diabetic (NOD) mice (54). The ability of eTACs to induce peripheral tolerance in TLOs is yet to be demonstrated, but expression of AIRE in these cells has been linked to non-canonical NF- $\kappa \mathrm{B}$ activation, which contributes to peripheral tolerance induction (55). Finally, fibroblastic reticular cells (FRCs) express and present peripheral tissue-restricted antigen to $\mathrm{T}$ cells as part of the peripheral tolerance mechanism, and their ability to stimulate $\mathrm{T}$ cells is altered depending on the inflammatory state of the tissue (56). These cell types have also been detected in TLOs, again pointing to roles in directing the immune response that unfolds within $(5,45,57)$.

While the presence in TLOs of each of the APCs described thus far has been robustly reported in the literature and across a variety of TLOs, in the vast majority of cases there has been limited or no direct investigation of actual antigen presentation in these tissues. What mechanisms exist to allow TLO-associated APCs access to antigen? Who are the main APCs presenting antigen, what are the nature of the antigens, and what are the ultimate immunological consequences of antigen presentation in TLOs?

\section{ACQUIRING ANTIGEN FOR PRESENTATION}

In the case of LNs, DCs carrying antigen acquired directly in a peripheral tissue migrate via the lymphatic vessels and enter the subcapsular sinus (SCS). Here, the DCs must traverse from the SCS ceiling to the floor, cross the dense parenchyma, and enter the paracortex. Small antigens can also drain freely through the lymphatic bed to the SCS. These antigens can be accessed by DCs already residing within the $\mathrm{LN}$ as they pass through conduits linking the SCS and HEVs $(58,59)$. A comparable conduit system is present in the follicular regions, allowing similar access to antigen by $\mathrm{B}$ cells $(60,61)$. The follicles themselves are positioned directly adjacent to the SCS and may facilitate B cell acquisition of soluble antigen, potentially draining through SCS pores $(62,63)$ or presented by SCS macrophages (64-66).
Another possibility is that B cells could acquire unprocessed antigen from DCs (67). In this instance, uptake by the DC would likely involve the Fc $\gamma$ RIIB receptor, allowing the antigen to remain unprocessed and recycled to the cell surface (68). Larger antigens acquired by non-cognate B cells can be further transported to FDCs in a complement-dependent way.

But what happens in a TLO? To date, direct data pertaining to antigen handling within TLOs is scarce. One might speculate as to the relevance of lymphatics and conduits to antigen transport to/within TLOs since, in general, the majority of TLOs do not demonstrate a distinct capsule or SCS, and form locally at the peripheral site of antigenic challenge. Yet lymphatic vessels do appear to be present in TLOs, such as those seen in ATLOs, iBALT, and pancreatic and thyroid infiltrate $(5,18,24,69)$. But their direct contribution in antigen transport is open for debate [as reviewed in Ref. (22)]. Splenic white pulp lacks afferent lymphatics but demonstrates series of organized cellular transport mechanisms [involving marginal zone macrophages, B cells and DCs (70)] along with a conduit network directly linked to the blood stream (71). As in the LN conduit system, transport of antigen/molecules is similarly size restricted, but does represent one way in which small molecules can be transported to particular compartments within the TLO. ATLOs demonstrate ER-TR7 ${ }^{+}$reticular networks consistent with the presence of conduits. Indeed, conduit structures were seen to extend through the $\mathrm{T}$ cell areas terminating adjacent to HEVs of the ATLO. In addition, these conduits were able to channel only small particles $(10 \mathrm{kDa})$ and not larger particles from the adventitia following i.v. administration (5). Evidence of conduit-like structures have been reported in both human and murine studies and in a variety of tertiary lymphoid tissues found in pancreas, kidney, salivary glands, and liver (57). So, it seems likely that an additional contribution of conduits and lymphatics in the instance of TLOs may relate to antigen transport, allowing small molecule percolation throughout the ectopic lymphoid organ, while, as in other lymphoid organs, their major role likely relates to cellular trafficking (transport of chemokines to HEVs in the case of conduits, and perhaps efferent lymphatic functions for removal of inflammatory cells and mediators from the affected tissue). Mechanisms of antigen handling and presentation in LNs vs. TLOs are illustrated in Figure 1.

\section{ANTIGEN PRESENTATION IN TLOS}

We have recently extensively studied antigen presentation in

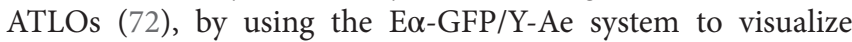
antigen uptake through a GFP tag and tracking of E $\alpha$ peptide/ MHC-II presentation using a commercially available (Y-Ae) Ab (73-75). In the case of ATLO APCs, acquisition and presentation of soluble antigen upon MHC class II occurs within a matter of hours (72). However, unlike in the LN, presentation in the ATLO occurs equally across the major APC populations, perhaps more consistent with free diffusion of the antigen rather than transport to defined niches and compartments (72). Around $80 \%$ of the CD $11 c^{\text {hi }} \mathrm{MHC}^{-\mathrm{II}^{+}}$APCs were monocyte-derived CD11b ${ }^{+} \mathrm{DC}$ -

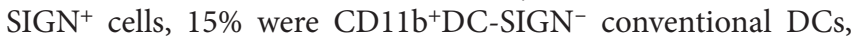
and $5 \% \mathrm{CD}^{1} \mathrm{~b}^{-} \mathrm{DC}-\mathrm{SIGN}^{-}$lymphoid DCs. The majority (80\%) of $\mathrm{MHC}-\mathrm{II}^{+} \mathrm{CD} 11 \mathrm{c}^{\mathrm{lo} /-}$ APCs were $\mathrm{CD} 19^{+} \mathrm{CD} 11 \mathrm{~b}^{-} \mathrm{B}$ cells and $10 \%$ 


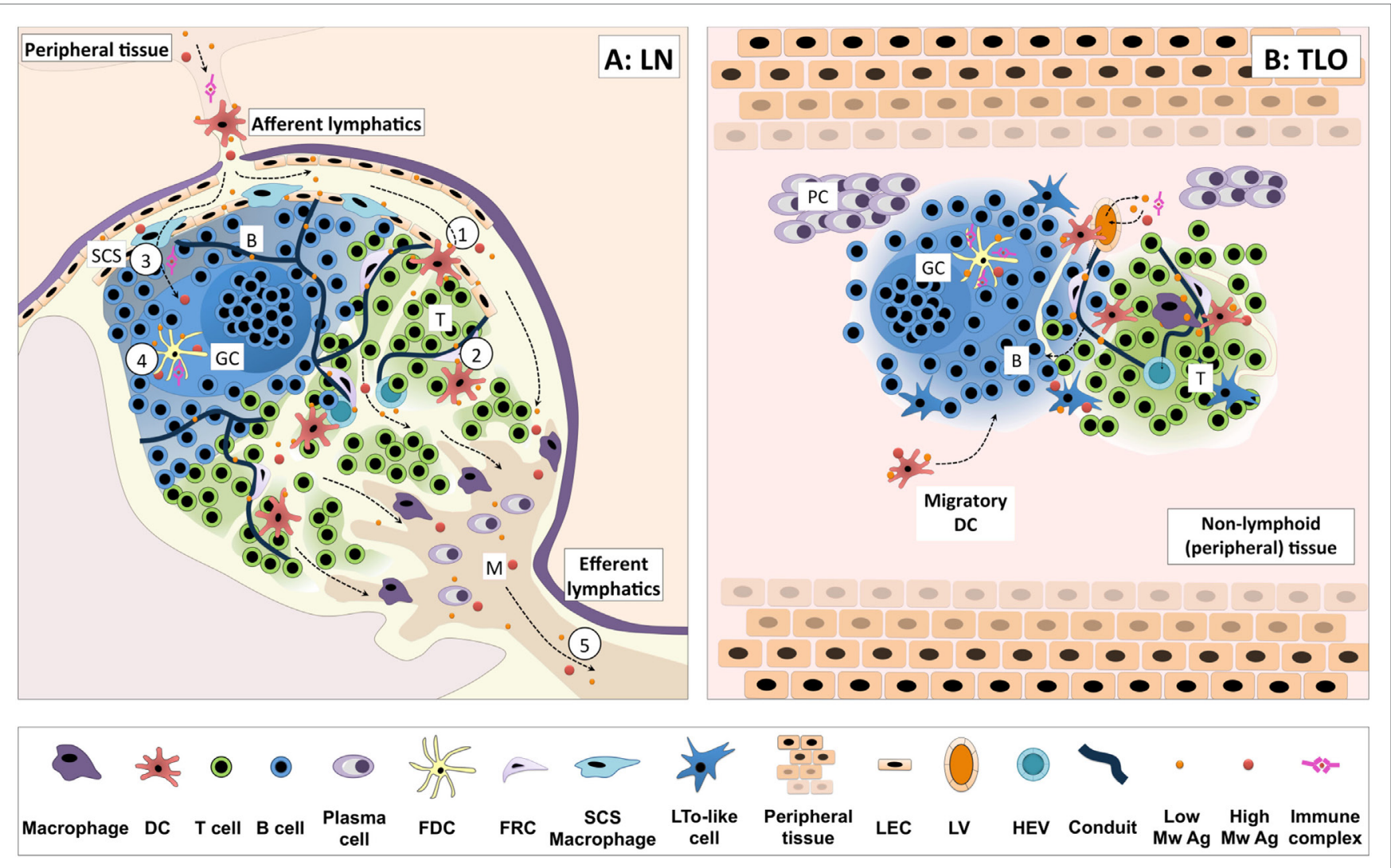

FIGURE 1 | Antigen handling and presentation in lymph nodes vs. TLOs. (A) Antigen reaches lymph nodes (LNs) via the afferent lymphatics, transported by dendritic cells (DCs) or freely draining from the peripheral tissues. Migratory DCs cross the subcapsular sinus (SCS) and enter the paracortex ( $\mathrm{T}$ cell area), migrating in response to appropriate chemotactic cues (1). Here, they encounter T cells searching for cognate peptide-MHC complexes. DCs residing within $\mathrm{T}$ cell areas can also sample small soluble molecules from a network of conduits traversing the paracortex (2). Additionally, small soluble antigens may be accessed by B cells via pores in the endothelial layer or transported by SCS macrophages, as is the case for larger antigens and immune complexes (3). Such antigen can be further transferred to FDCs for presentation to B cells (4). Freely draining antigen may also exit the LN efferent lymphatic and reach the next lymph node in the chain (5). (B) In general, tertiary lymphoid organs (TLOs) lack a defined capsule, which may allow more free diffusion of antigen through the structure. Lymphatic and conduit-like structures have been identified in TLOs, and may function in an analogous fashion to those in SLOs, although this has yet to be formally demonstrated. Similar cellular compartmentalization is observed between TLOs and SLOs, and they share many common antigen-presenting cell populations. Indeed, the migration of DCs from surrounding tissues to the TLOs has been observed in several models of TLO formation. Thus, TLOs likely share common pathways for handling cell-associated and free antigen with SLOs to optimize the functioning of adaptive immune responses. Key: B, B cell follicle; T, T cell area; SCS, subcapsular sinus; GC, germinal center; M, medulla; PC, plasma cell niche; DC, dendritic cell; FDC, follicular DC; FRC, fibroblastic reticular cells; LTo, lymphoid tissue organizer; LEC, lymphatic endothelial cell; LV, lymphatic vessel; HEV, high endothelial venule; low/high Mw Ag, low/high molecular weight antigen.

were $\mathrm{CD}_{19}{ }^{-} \mathrm{CD} 11 \mathrm{~b}^{+}$macrophages. $1-2 \%$ of $\mathrm{CD} 11 \mathrm{c}^{\text {lo }}$ Siglec $\mathrm{H}^{+}$ plasmacytoid dendritic cells (pDCs) were also detectable within the ATLO. Following E $\alpha$ i.v. administration, around 55\% of MHC-II ${ }^{\text {hiY }}-\mathrm{Ae}^{+}$APCs were CD $11 c^{+} \mathrm{CD} 11 \mathrm{~b}^{+} \mathrm{DC}-\mathrm{SIGN}^{+}$, followed by $\mathrm{B}$ cells, conventional DCs, CD11 $\mathrm{c}^{\mathrm{lo} /}$ macrophages, and lymphoid DCs. None of the pDCs were $\mathrm{Y}-\mathrm{Ae}^{+}$, in contrast with what was previously observed by us in the aorta of early atherosclerotic mice $(73,74)$. In summary, DCs, macrophages and B cells were the major ATLO APCs.

Altering the kinetics of antigen presentation is known to influence the outcome of $\mathrm{T}$ cell responses (76-81). How, or even if, differences in antigen handling between TLOs and LNs impact on the ensuing immune response is unknown. While TLOs form at sites of active antigen presentation and functional lymphocyte responses, they also support entry and priming of naïve $\mathrm{T}$ cells within the tissue. Intranasal delivered mature BM-derived DCs pulsed with OVApeptide (SIINFEKL) were readily detected in iBALT and able to induce proliferative responses in naïve OT-I $\mathrm{CD}^{+} \mathrm{T}$ cells (2). Similarly, OT-I T cells proliferated in tumorassociated tertiary lymphoid structures following interaction with DCs (82). Notably, multiphoton imaging revealed that the dynamics of naïve $\mathrm{T}$ cell migration and interaction with antigen-bearing DCs in iBALT (2) was consistent with the three phases of $\mathrm{T}$ cell priming reported by Mempel et al. (83). A similar observation relating to $\mathrm{CD} 4^{+} \mathrm{T}$ cell behavior showed OT-II T cells clustering around ATLO resident $\mathrm{CD} 11 \mathrm{c}^{+}$cells following antigen challenge (72), reminiscent of that seen in $\mathrm{LN}$ priming of $\mathrm{CD} 4^{+}$ $\mathrm{T}$ cells (84). Priming of naïve $\mathrm{T}$ cells within ectopic structures may have beneficial or detrimental effects depending upon context of the ongoing immune response, being beneficial in infectious 
disease where secondary infection is a risk or contributing to epitope spreading in autoimmune disease.

Another possible role of TLOs may be the provision of a localized concentration of antigen, either from an infection or, in the case of autoimmunity, self-antigen(s). Although some transient TLOs disperse after antigen clearance, as in iBALT, this dissolution can be delayed by up to 3 weeks after the infection has resolved (2). However, it may be possible that this lag period exists due to some antigen in the form of immune complexes being displayed by FDCs. In either respect, this persistence may enable more efficient development and maintenance of memory cells, as suggested by data from ATLO and allograft studies (72, 85), and therefore a more effective in situ response to subsequent re-infection or antigen challenge.

\section{FUTURE DIRECTIONS}

Clearly, many questions remain unresolved with regard to the importance and mechanism(s) of antigen presentation within TLOs, where lack of isolation or encapsulation may, in many instances, allow for a much greater degree of exposure to free antigen for all cells within the tissue. Details such as in situ neoantigen availability, the timing of antigen arrival and presentation, the context in which antigen is encountered by specific cells, and the ability of those cells to receive appropriate co-stimulatory or tolerogenic signals remain to be elucidated.

With advances in cellular imaging techniques, in combination with trackable antigens and cell populations, the answers to such questions are becoming increasingly tangible. The elegant application of such approaches has successfully furthered our understanding of soluble antigen and immune complex trafficking and

\section{REFERENCES}

1. Aloisi F, Pujol-Borrell R. Lymphoid neogenesis in chronic inflammatory diseases. Nat Rev Immunol (2006) 6(3):205-17. doi:10.1038/nri1786

2. Halle S, Dujardin HC, Bakocevic N, Fleige H, Danzer H, Willenzon S, et al. Induced bronchus-associated lymphoid tissue serves as a general priming site for T cells and is maintained by dendritic cells. J Exp Med (2009) 206(12):2593-601. doi:10.1084/jem.20091472

3. GeurtsvanKessel CH, Willart MA, Bergen IM, van Rijt LS, Muskens F, Elewaut D, et al. Dendritic cells are crucial for maintenance of tertiary lymphoid structures in the lung of influenza virus-infected mice. J Exp Med (2009) 206(11):2339-49. doi:10.1084/jem.20090410

4. Jupelli M, Shimada K, Chiba N, Slepenkin A, Alsabeh R, Jones HD, et al. Chlamydia pneumoniae infection in mice induces chronic lung inflammation, iBALT formation, and fibrosis. PLoS One (2013) 8(10):e77447. doi:10.1371/ journal.pone.0077447

5. Grabner R, Lotzer K, Dopping S, Hildner M, Radke D, Beer M, et al. Lymphotoxin beta receptor signaling promotes tertiary lymphoid organogenesis in the aorta adventitia of aged ApoE-/- mice. J Exp Med (2009) 206(1):233-48. doi:10.1084/jem.20080752

6. Yin C, Mohanta SK, Srikakulapu P, Weber C, Habenicht AJR. Artery tertiary lymphoid organs: powerhouses of atherosclerosis immunity. Front Immunol (2016) 7:387. doi:10.3389/fimmu.2016.00387

7. Hiraoka N, Ino Y, Yamazaki-Itoh R. Tertiary lymphoid organs in cancer tissues. Front Immunol (2016) 7:244. doi:10.3389/fimmu.2016.00244

8. Sautès-Fridman C, Lawand M, Giraldo NA, Kaplon H, Germain C, Fridman $\mathrm{WH}$, et al. Tertiary lymphoid structures in cancers: prognostic value, regulation, and manipulation for therapeutic intervention. Front Immunol (2016) 7:407. doi:10.3389/fimmu.2016.00407 related immune cell interactions in SLOs (86-88). By identifying key antigen handling routes and responding cells in a dynamic setting, the possibility to develop antigen-specific therapeutics targeting TLO functions becomes a more exciting and viable option.

The identification of key antigen specificities must also be allied with such imaging approaches. The increasing power of next generation sequencing techniques makes the sequencing of both $\mathrm{T}$ and $\mathrm{B}$ cell repertoires $(89,90)$ in TLOs a reality. Biases in repertoire indicating clonal responses could yield valuable information pertaining to antigen specificity. At the very least, key clonal populations could be identified and used as biomarkers or even be targeted to prevent or augment antigen-specific responses as required.

\section{AUTHOR CONTRIBUTIONS}

All authors listed have made substantial, direct, and intellectual contribution to the work and approved it for publication.

\section{FUNDING}

This work was supported by the British Heart Foundation grants PG/06/083/21198, PG/12/81/29897 and RE/13/5/30177; the Medical Research Scotland grant 276 FRG-L-0806; the European Commission Marie Skłodowska-Curie Individual Fellowships 661369; and an Oliver Bird Studentship by the Nuffield Foundation. MB and RB are members of the Arthritis Research UK - Rheumatoid Arthritis Pathogenesis Centre of Excellence (RACE) - part-funded by Arthritis Research UK through grant number 20298.

9. Pitzalis C, Jones GW, Bombardieri M, Jones SA. Ectopic lymphoid-like structures in infection, cancer and autoimmunity. Nat Rev Immunol (2014) 14(7):447-62. doi:10.1038/nri3700

10. Weyand CM, Goronzy JJ. Ectopic germinal center formation in rheumatoid synovitis. Ann N Y Acad Sci (2003) 987:140-9. doi:10.1111/j.1749-6632.2003. tb06042.x

11. Bombardieri M, Pitzalis C. Ectopic lymphoid neogenesis and lymphoid chemokines in Sjogren's syndrome: at the interplay between chronic inflammation, autoimmunity and lymphomagenesis. Curr Pharm Biotechnol (2012) 13(10):1989-96. doi:10.2174/138920112802273209

12. Serafini B, Rosicarelli B, Magliozzi R, Stigliano E, Aloisi F. Detection of ectopic B-cell follicles with germinal centers in the meninges of patients with secondary progressive multiple sclerosis. Brain Pathol (2004) 14(2):164-74. doi:10.1 111/j.1750-3639.2004.tb00049.x

13. Tumanov A, Kuprash D, Lagarkova M, Grivennikov S, Abe K, Shakhov A, et al. Distinct role of surface lymphotoxin expressed by B cells in the organization of secondary lymphoid tissues. Immunity (2002) 17(3):239-50. doi:10.1016/ S1074-7613(02)00397-7

14. Kratz A, Campos-Neto A, Hanson MS, Ruddle NH. Chronic inflammation caused by lymphotoxin is lymphoid neogenesis. J Exp Med (1996) 183(4):1461-72. doi:10.1084/jem.183.4.1461

15. Barone F, Nayar S, Campos J, Cloake T, Withers DR, Toellner KM, et al. IL-22 regulates lymphoid chemokine production and assembly of tertiary lymphoid organs. Proc Natl Acad Sci U S A (2015) 112(35):11024-9. doi:10.1073/ pnas. 1503315112

16. Marinkovic T, Garin A, Yokota Y, Fu YX, Ruddle NH, Furtado GC, et al. Interaction of mature $\mathrm{CD} 3+\mathrm{CD} 4+\mathrm{T}$ cells with dendritic cells triggers the development of tertiary lymphoid structures in the thyroid. J Clin Invest (2006) 116(10):2622-32. doi:10.1172/jci28993 
17. Moyron-Quiroz JE, Rangel-Moreno J, Kusser K, Hartson L, Sprague F, Goodrich S, et al. Role of inducible bronchus associated lymphoid tissue (iBALT) in respiratory immunity. Nat Med (2004) 10(9):927-34. doi:10.1038/ nm1091

18. Rangel-Moreno J, Hartson L, Navarro C, Gaxiola M, Selman M, Randall TD. Inducible bronchus-associated lymphoid tissue (iBALT) in patients with pulmonary complications of rheumatoid arthritis. J Clin Invest (2006) 116(12):3183-94. doi:10.1172/jci28756

19. Jones GW, Hill DG, Jones SA. Understanding immune cells in tertiary lymphoid organ development: it is all starting to come together. Front Immunol (2016) 7:401. doi:10.3389/fimmu.2016.00401

20. Guedj K, Khallou-Laschet J, Clement M, Morvan M, Gaston AT, Fornasa G, et al. M1 macrophages act as LT $\beta R$-independent lymphoid tissue inducer cells during atherosclerosis-related lymphoid neogenesis. Cardiovasc Res (2014) 101(3):434-43. doi:10.1093/cvr/cvt263

21. McDonald KG, McDonough JS, Newberry RD. Adaptive immune responses are dispensable for isolated lymphoid follicle formation: antigen-naive, lymphotoxin-sufficient B lymphocytes drive the formation of mature isolated lymphoid follicles. JImmunol (2005) 174(9):5720-8. doi:10.4049/ jimmunol.174.9.5720

22. Ruddle NH. Lymphatic vessels and tertiary lymphoid organs. J Clin Invest (2014) 124(3):953-9. doi:10.1172/jci71611

23. Kambayashi T, Laufer TM. Atypical MHC class II-expressing antigen-presenting cells: can anything replace a dendritic cell? Nat Rev Immunol (2014) 14(11):719-30. doi:10.1038/nri3754

24. Muniz LR, Pacer ME, Lira SA, Furtado GC. A critical role for dendritic cells in the formation of lymphatic vessels within tertiary lymphoid structures. J Immunol (2011) 187(2):828-34. doi:10.4049/jimmunol.1004233

25. Browning JL, Allaire N, Ngam-Ek A, Notidis E, Hunt J, Perrin S, et al. Lymphotoxin-beta receptor signaling is required for the homeostatic control of HEV differentiation and function. Immunity (2005) 23(5):539-50. doi:10.1016/j.immuni.2005.10.002

26. Ludewig B, Odermatt B, Landmann S, Hengartner H, Zinkernagel RM. Dendritic cells induce autoimmune diabetes and maintain disease via de novo formation of local lymphoid tissue. J Exp Med (1998) 188(8):1493-501. doi:10.1084/jem.188.8.1493

27. Dieu-Nosjean MC, Antoine M, Danel C, Heudes D, Wislez M, Poulot V, et al. Long-term survival for patients with non-small-cell lung cancer with intratumoral lymphoid structures. J Clin Oncol (2008) 26(27):4410-7. doi:10.1200/ JCO.2007.15.0284

28. Germain C, Gnjatic S, Tamzalit F, Knockaert S, Remark R, Goc J, et al. Presence of B cells in tertiary lymphoid structures is associated with a protective immunity in patients with lung cancer. Am J Respir Crit Care Med (2014) 189(7):832-44. doi:10.1164/rccm.201309-1611OC

29. Cho HJ, Shashkin P, Gleissner CA, Dunson D, Jain N, Lee JK, et al. Induction of dendritic cell-like phenotype in macrophages during foam cell formation. Physiol Genomics (2007) 29(2):149-60. doi:10.1152/physiolgenomics. 00051.2006

30. Chen X, Jensen PE. The role of B lymphocytes as antigen-presenting cells. Arch Immunol Ther Exp (2008) 56(2):77-83. doi:10.1007/s00005-0080014-5

31. Srikakulapu P, Hu D, Yin C, Mohanta SK, Bontha SV, Peng L, et al. Artery tertiary lymphoid organs control multilayered territorialized atherosclerosis B-cell responses in aged ApoE-/- mice. Arterioscler Thromb Vasc Biol (2016) 36(6):1174-85. doi:10.1161/ATVBAHA.115.306983

32. Germain C, Gnjatic S, Dieu-Nosjean MC. Tertiary lymphoid structure-associated B cells are key players in anti-tumor immunity. Front Immunol (2015) 6:67. doi:10.3389/fimmu.2015.00067

33. Jones GW, Jones SA. Ectopic lymphoid follicles: inducible centres for generating antigen-specific immune responses within tissues. Immunology (2016) 147(2):141-51. doi:10.1111/imm.12554

34. MacLennan IC. Germinal centers. Annu Rev Immunol (1994) 12:117-39. doi:10.1146/annurev.iy.12.040194.001001

35. Fu YX, Huang G, Wang Y, Chaplin DD. B lymphocytes induce the formation of follicular dendritic cell clusters in a lymphotoxin alpha-dependent fashion. J Exp Med (1998) 187(7):1009-18. doi:10.1084/jem.187.7.1009

36. Allen CD, Cyster JG. Follicular dendritic cell networks of primary follicles and germinal centers: phenotype and function. Semin Immunol (2008) 20(1):14-25. doi:10.1016/j.smim.2007.12.001
37. Ansel KM, Ngo VN, Hyman PL, Luther SA, Forster R, Sedgwick JD, et al. A chemokine-driven positive feedback loop organizes lymphoid follicles. Nature (2000) 406(6793):309-14. doi:10.1038/35018581

38. Le Pottier L, Devauchelle V, Fautrel A, Daridon C, Saraux A, Youinou P, et al. Ectopic germinal centers are rare in Sjogren's syndrome salivary glands and do not exclude autoreactive B cells. J Immunol (2009) 182(6):3540-7. doi:10.4049/jimmunol.0803588

39. Heesters BA, Myers RC, Carroll MC. Follicular dendritic cells: dynamic antigen libraries. Nat Rev Immunol (2014) 14(7):495-504. doi:10.1038/ nri3689

40. Kranich J, Krautler NJ. How follicular dendritic cells shape the B-cell antigenome. Front Immunol (2016) 7:225. doi:10.3389/fimmu.2016.00225

41. Victoratos P, Kollias G. Induction of autoantibody-mediated spontaneous arthritis critically depends on follicular dendritic cells. Immunity (2009) 30(1):130-42. doi:10.1016/j.immuni.2008.10.019

42. Drayton DL, Ying X, Lee J, Lesslauer W, Ruddle NH. Ectopic LT alpha beta directs lymphoid organ neogenesis with concomitant expression of peripheral node addressin and a HEV-restricted sulfotransferase. JExp Med (2003) 197(9):1153-63. doi:10.1084/jem.20021761

43. Moser B, Schaerli P, Loetscher P. CXCR5(+) T cells: follicular homing takes center stage in T-helper-cell responses. Trends Immunol (2002) 23(5):250-4. doi:10.1016/S1471-4906(02)02218-4

44. Barone F, Bombardieri M, Manzo A, Blades MC, Morgan PR, Challacombe SJ, et al. Association of CXCL13 and CCL21 expression with the progressive organization of lymphoid-like structures in Sjogren's syndrome. Arthritis Rheum (2005) 52(6):1773-84. doi:10.1002/art.21062

45. Stranford S, Ruddle NH. Follicular dendritic cells, conduits, lymphatic vessels, and high endothelial venules in tertiary lymphoid organs: parallels with lymph node stroma. Front Immunol (2012) 3:350. doi:10.3389/fimmu.2012. 00350

46. Fleige H, Ravens S, Moschovakis GL, Bölter J, Willenzon S, Sutter G, et al. IL-17-induced CXCL12 recruits B cells and induces follicle formation in BALT in the absence of differentiated FDCs. J Exp Med (2014) 211(4):643-51. doi:10.1084/jem.20131737

47. El Shikh ME, Pitzalis C. Follicular dendritic cells in health and disease. Front Immunol (2012) 3:292. doi:10.3389/fimmu.2012.00292

48. Ishimaru N, Arakaki R, Yoshida S, Yamada A, Noji S, Hayashi Y. Expression of the retinoblastoma protein RbAp48 in exocrine glands leads to Sjogren's syndrome-like autoimmune exocrinopathy. J Exp Med (2008) 205(12):2915-27. doi:10.1084/jem.20080174

49. Kapsogeorgou EK, Moutsopoulos HM, Manoussakis MN. Functional expression of a costimulatory B7.2 (CD86) protein on human salivary gland epithelial cells that interacts with the CD28 receptor, but has reduced binding to CTLA4. J Immunol (2001) 166(5):3107-13. doi:10.4049/jimmunol. 166.5.3107

50. Dimitriou ID, Kapsogeorgou EK, Moutsopoulos HM, Manoussakis MN. CD40 on salivary gland epithelial cells: high constitutive expression by cultured cells from Sjogren's syndrome patients indicating their intrinsic activation. Clin Exp Immunol (2002) 127(2):386-92. doi:10.1046/j.1365-2249.2002. 01752.x

51. Tsunawaki S, Nakamura S, Ohyama Y, Sasaki M, Ikebe-Hiroki A, Hiraki A, et al. Possible function of salivary gland epithelial cells as nonprofessional antigen-presenting cells in the development of Sjogren's syndrome. J Rheumatol (2002) 29(9):1884-96.

52. Londei M, Lamb JR, Bottazzo GF, Feldmann M. Epithelial cells expressing aberrant MHC class II determinants can present antigen to cloned human T cells. Nature (1984) 312(5995):639-41. doi:10.1038/312639a0

53. Cohen JN, Guidi CJ, Tewalt EF, Qiao H, Rouhani SJ, Ruddell A, et al. Lymph node-resident lymphatic endothelial cells mediate peripheral tolerance via Aire-independent direct antigen presentation. J Exp Med (2010) 207(4):681-8. doi:10.1084/jem.20092465

54. Gardner JM, Devoss JJ, Friedman RS, Wong DJ, Tan YX, Zhou X, et al. Deletional tolerance mediated by extrathymic Aire-expressing cells. Science (2008) 321(5890):843-7. doi:10.1126/science.1159407

55. van Delft MA, Huitema LF, Tas SW. The contribution of NF-кB signalling to immune regulation and tolerance. Eur J Clin Invest (2015) 45(5):529-39. doi:10.1111/eci.12430

56. Fletcher AL, Lukacs-Kornek V, Reynoso ED, Pinner SE, Bellemare-Pelletier A, Curry MS, et al. Lymph node fibroblastic reticular cells directly present 
peripheral tissue antigen under steady-state and inflammatory conditions. J Exp Med (2010) 207(4):689-97. doi:10.1084/jem.20092642

57. Link A, Hardie DL, Favre S, Britschgi MR, Adams DH, Sixt M, et al. Association of T-zone reticular networks and conduits with ectopic lymphoid tissues in mice and humans. Am J Pathol (2011) 178(4):1662-75. doi:10.1016/j. ajpath.2010.12.039

58. Bajenoff M, Granjeaud S, Guerder S. The strategy of T cell antigen-presenting cell encounter in antigen-draining lymph nodes revealed by imaging of initial T cell activation. J Exp Med (2003) 198(5):715-24. doi:10.1084/ jem.20030167

59. Sixt M, Kanazawa N, Selg M, Samson T, Roos G, Reinhardt DP, et al. The conduit system transports soluble antigens from the afferent lymph to resident dendritic cells in the T cell area of the lymph node. Immunity (2005) 22(1):19-29. doi:10.1016/j.immuni.2004.11.013

60. Roozendaal R, Mempel TR, Pitcher LA, Gonzalez SF, Verschoor A, Mebius RE, et al. Conduits mediate transport of low-molecular-weight antigen to lymph node follicles. Immunity (2009) 30(2):264-76. doi:10.1016/j.immuni.2008. 12.014

61. Bajenoff M, Germain RN. B-cell follicle development remodels the conduit system and allows soluble antigen delivery to follicular dendritic cells. Blood (2009) 114(24):4989-97. doi:10.1182/blood-2009-06-229567

62. Clark SL Jr. The reticulum of lymph nodes in mice studied with the electron microscope. Am J Anat (1962) 110:217-57. doi:10.1002/aja.1001100303

63. Pape KA, Catron DM, Itano AA, Jenkins MK. The humoral immune response is initiated in lymph nodes by B cells that acquire soluble antigen directly in the follicles. Immunity (2007) 26(4):491-502. doi:10.1016/j.immuni.2007. 02.011

64. Carrasco YR, Batista FD. B cells acquire particulate antigen in a macrophage-rich area at the boundary between the follicle and the subcapsular sinus of the lymph node. Immunity (2007) 27(1):160-71. doi:10.1016/j. immuni.2007.06.007

65. Junt T, Moseman EA, Iannacone M, Massberg S, Lang PA, Boes M, et al. Subcapsular sinus macrophages in lymph nodes clear lymph-borne viruses and present them to antiviral B cells. Nature (2007) 450(7166):110-4. doi:10.1038/nature06287

66. Phan TG, Grigorova I, Okada T, Cyster JG. Subcapsular encounter and complement-dependent transport of immune complexes by lymph node B cells. Nat Immunol (2007) 8(9):992-1000. doi:10.1038/ni1494

67. Qi H, Egen JG, Huang AY, Germain RN. Extrafollicular activation of lymph node B cells by antigen-bearing dendritic cells. Science (2006) 312(5780):1672-6. doi:10.1126/science.1125703

68. Delamarre L, Pack M, Chang H, Mellman I, Trombetta ES. Differential lysosomal proteolysis in antigen-presenting cells determines antigen fate. Science (2005) 307(5715):1630-4. doi:10.1126/science.1108003

69. Penaranda C, Tang Q, Ruddle NH, Bluestone JA. Prevention of diabetes by FTY720-mediated stabilization of peri-islet tertiary lymphoid organs. Diabetes (2010) 59(6):1461-8. doi:10.2337/db09-1129

70. Kraal G. Cells in the marginal zone of the spleen. Int Rev Cytol (1992) 132:31-74. doi:10.1016/S0074-7696(08)62453-5

71. Nolte MA, Belien JA, Schadee-Eestermans I, Jansen W, Unger WW, van Rooijen N, et al. A conduit system distributes chemokines and small blood-borne molecules through the splenic white pulp. JExp Med (2003) 198(3):505-12. doi:10.1084/jem.20021801

72. Hu D, Mohanta SK, Yin C, Peng L, Ma Z, Srikakulapu P, et al. Artery tertiary lymphoid organs control aorta immunity and protect against atherosclerosis via vascular smooth muscle cell lymphotoxin beta receptors. Immunity (2015) 42(6):1100-15. doi:10.1016/j.immuni.2015.05.015

73. Macritchie N, Grassia G, Sabir SR, Maddaluno M, Welsh P, Sattar N, et al. Plasmacytoid dendritic cells play a key role in promoting atherosclerosis in apolipoprotein E-deficient mice. Arterioscler Thromb Vasc Biol (2012) 32(11):2569-79. doi:10.1161/ATVBAHA.112.251314

74. Sage AP, Murphy D, Maffia P, Masters LM, Sabir SR, Baker LL, et al. MHC Class II-restricted antigen presentation by plasmacytoid dendritic cells drives proatherogenic T cell immunity. Circulation (2014) 130(16):1363-73. doi:10.1161/CIRCULATIONAHA.114.011090
75. Maddaluno M, MacRitchie N, Grassia G, Ialenti A, Butcher JP, Garside P, et al. Murine aortic smooth muscle cells acquire, though fail to present exogenous protein antigens on major histocompatibility complex class II molecules. Biomed Res Int (2014) 2014:949845. doi:10.1155/2014/949845

76. Obst R, van Santen HM, Melamed R, Kamphorst AO, Benoist C, Mathis D. Sustained antigen presentation can promote an immunogenic $\mathrm{T}$ cell response, like dendritic cell activation. Proc Natl Acad Sci U S A (2007) 104(39):15460-5. doi:10.1073/pnas.0707331104

77. Celli S, Lemaitre F, Bousso P. Real-time manipulation of T cell-dendritic cell interactions in vivo reveals the importance of prolonged contacts for CD4+ T cell activation. Immunity (2007) 27(4):625-34. doi:10.1016/j. immuni.2007.08.018

78. Baumjohann D, Preite S, Reboldi A, Ronchi F, Ansel KM, Lanzavecchia A, et al. Persistent antigen and germinal center B cells sustain T follicular helper cell responses and phenotype. Immunity (2013) 38(3):596-605. doi:10.1016/j. immuni.2012.11.020

79. Henrickson SE, Perro M, Loughhead SM, Senman B, Stutte S, Quigley M, et al. Antigen availability determines CD8(+) T cell-dendritic cell interaction kinetics and memory fate decisions. Immunity (2013) 39(3):496-507. doi:10.1016/j.immuni.2013.08.034

80. Rabenstein H, Behrendt AC, Ellwart JW, Naumann R, Horsch M, Beckers J, et al. Differential kinetics of antigen dependency of CD4+ and CD8+ T cells. J Immunol (2014) 192(8):3507-17. doi:10.4049/jimmunol.1302725

81. Benson RA, MacLeod MK, Hale BG, Patakas A, Garside P, Brewer JM. Antigen presentation kinetics control $\mathrm{T}$ cell/dendritic cell interactions and follicular helper T cell generation in vivo. Elife (2015) 4. doi:10.7554/eLife.06994

82. Joshi NS, Akama-Garren EH, Lu Y, Lee DY, Chang GP, Li A, et al. Regulatory $\mathrm{T}$ cells in tumor-associated tertiary lymphoid structures suppress anti-tumor T cell responses. Immunity (2015) 43(3):579-90. doi:10.1016/j. immuni.2015.08.006

83. Mempel TR, Henrickson SE, Von Andrian UH. T-cell priming by dendritic cells in lymph nodes occurs in three distinct phases. Nature (2004) 427(6970):154-9. doi:10.1038/nature02238

84. Zinselmeyer BH, Dempster J, Gurney AM, Wokosin D, Miller M, Ho H, et al. In situ characterization of $\mathrm{CD} 4+\mathrm{T}$ cell behavior in mucosal and systemic lymphoid tissues during the induction of oral priming and tolerance. J Exp Med (2005) 201(11):1815-23. doi:10.1084/jem.20050203

85. Nasr IW, Reel M, Oberbarnscheidt MH, Mounzer RH, Baddoura FK, Ruddle NH, et al. Tertiary lymphoid tissues generate effector and memory T cells that lead to allograft rejection. Am J Transplant (2007) 7(5):1071-9. doi:10.1111/j.1600-6143.2007.01756.x

86. Itano AA, Jenkins MK. Antigen presentation to naive $\mathrm{CD} 4 \mathrm{~T}$ cells in the lymph node. Nat Immunol (2003) 4(8):733-9. doi:10.1038/ni957

87. Cyster JG. B cell follicles and antigen encounters of the third kind. Nat Immunol (2010) 11(11):989-96. doi:10.1038/ni.1946

88. Germain RN, Robey EA, Cahalan MD. A decade of imaging cellular motility and interaction dynamics in the immune system. Science (2012) 336(6089):1676-81. doi:10.1126/science.1221063

89. Robins H. Immunosequencing: applications of immune repertoire deep sequencing. Curr Opin Immunol (2013) 25(5):646-52. doi:10.1016/j.coi.2013. 09.017

90. Calis JJ, Rosenberg BR. Characterizing immune repertoires by high throughput sequencing: strategies and applications. Trends Immunol (2014) 35(12):581-90. doi:10.1016/j.it.2014.09.004

Conflict of Interest Statement: The authors declare that the research was conducted in the absence of any commercial or financial relationships that could be construed as a potential conflict of interest.

Copyright $\odot 2016$ Hughes, Benson, Bedaj and Maffia. This is an open-access article distributed under the terms of the Creative Commons Attribution License (CC BY). The use, distribution or reproduction in other forums is permitted, provided the original author(s) or licensor are credited and that the original publication in this journal is cited, in accordance with accepted academic practice. No use, distribution or reproduction is permitted which does not comply with these terms. 